\title{
ยกด \\ Contribuição do Ensino a Distância em uma Unidade Curricular do Curso de Enfermagem
}

\author{
Stenio Nunes Alves*1, Cristiane Queixa Tilelli², Eduardo Henrique de \\ Matos Lima, Luis Fernando Soares ${ }^{4}$
}

\begin{abstract}
${ }^{1}$ Pesquisador, Laboratório de Insetos Vetores de Doenças, e professor/Universidade Federal de São João del-Rei. Campus Centro-Oeste Dona Lindu. Av. Sebastião Gonçalves Coelho, 400, Chanadour - Divinópolis - MG - Brasil stenioalves@ufsj.edu.br

2 Pesquisadora, Laboratório de Estudos em Neurociências das Epilepsias e Comorbidades, e professora/Universidade Federal de São João del-Rei. Campus Centro-Oeste Dona Lindu. Av. Sebastião Gonçalves Coelho, 400, Chanadour - Divinópolis - MG - Brasil ctilelli@ufsj.edu.br

3 Professor, Universidade Federal de São João del-Rei. Campus Centro-Oeste Dona Lindu. Av. Sebastião Gonçalves Coelho, 400, Chanadour - Divinópolis - MG - Brasil eduardohmlima@yahoo.com.br

4 Pesquisador, Laboratório de Desenvolvimento de Materiais Didáticos, e professor/Universidade Federal de São João del-Rei. Campus Centro-Oeste Dona Lindu. Av. Sebastião Gonçalves Coelho, 400, Chanadour Divinópolis - MG - Brasil Ifsoares@ufsj.edu.br
\end{abstract}

\section{Resumo}

A realização de aulas viabilizadas por meio de recursos digitais em ambientes virtuais de aprendizagem (AVAs) em cursos presenciais é uma estratégia pertinente diante do atual contexto sociotécnico, que pode contribuir com o processo pedagógico e promover maior aproximação de aluno, professor e tutor. Assim, o objetivo do presente estudo foi estruturar e desenvolver os conteúdos de Biologia Celular, por meio do AVA Moodle, como estratégia pedagógica para os alunos do primeiro período do curso de Enfermagem da Universidade Federal de São João del-Rei (UFSJ). Durante um semestre letivo, todos os estudantes do primeiro período tiveram acesso aos conteúdos on-line. As atividades mais acessadas foram os questionários sobre os componentes celulares e a bioquímica celular, seguidas por tarefas com pontuação e a visualização dos demais conteúdos do curso. Assim, diante de um cenário com ampla inserção das tecnologias digitais de informação e comunicação (TDIC) nos espaços individuais, sociais e profissionais, as universidades precisam repensar as possibilidades de desenvolvimento de propostas pedagógicas a partir de modelos de aprendizagem híbridos, ou seja, que combinam estratégias de ensino e aprendizagem on-line e presencial, conferindo maior flexibilidade e autonomia aos estudantes.

Palavras-chave: Moodle; Enfermagem; Biologia celular. 


\title{
Contribution of the Distance Education on a Curricular Unit of Nursing Course
}

\begin{abstract}
The realization of lectures supported by digital resources in digital learning environments (DLE) in traditional classroom courses is an appropriate strategy given the current technical-social context of the student. DLEs can contribute to the educational process and promote approximation of student, teacher and tutor. The objective of this study was to structure and develop Cell Biology content through the VLE Moodle, as a pedagogical strategy for students of the first period of the Nursing DLE Moodle, as a pedagogical strategy for students in the first contact with the undergraduate nursing course or the Federal University of São João del-Rei (UFSJ). During one semester, all students had access to the online content of the course. The most accessed activities were questionnaires on cell components and biochemistry, followed by scored exercises and visualization of other resources of the course. Faced with a scenario with broad integration of digital information and communication technologies (DICT) in individual, social and professional spaces, universities need to rethink the possibilities of development of education projects based on hybrid learning models, that is, combine teaching strategies, e-learning techiniques and traditional lectures providing greater flexibility and autonomy to students.
\end{abstract}

Keywords: Moodle; Nursing; Cell biology. 


\section{Introdução}

A universidade brasileira está passando por uma reformulação que vem seguindo os moldes do Processo de Bolonha, implantado na Europa no final da década de 1990. Esse processo tem como objetivo principal fazer com que os estudantes europeus ganhem competitividade num sistema universitário semelhante entre os países, que afere graus, diplomas, títulos universitários, currículos acadêmicos com programas de formação continuada reconhecida pelos países da Comunidade Europeia (Lima, Azevedo, \& Catani, 2008).

Nesse sentido, as Diretrizes Curriculares estabelecidas pelo Conselho Nacional de Educação (CNE) apontam para currículos flexíveis, integrados e sistêmicos, que atentem para conhecimentos, habilidades e atitudes de forma ampla, permitindo a atualização/reformulação dos projetos pedagógicos, da estrutura e do funcionamento dos cursos em bases interdisciplinares.

Uma das propostas que pode contribuir significativamente com esse processo é a Educação a Distância (EaD), principalmente depois da popularização das tecnologias digitais de informação e de comunicação (TDIC), o que vem favorecendo o aumento no nível de escolaridade, com o aperfeiçoamento e a contínua atualização profissional. A EaD tem como princípio manter a qualidade da educação com procedimentos e propostas de abordagem dos conteúdos curriculares que possibilitem todo o processo de desenvolvimento cognitivo, social, afetivo, profissional e ético dos alunos (Brasil, 2002).

A partir da expansão da EaD com a utilização das TDIC, também denominada elearning, a aprendizagem on-line em cursos presenciais passa a ser uma possibilidade de proposta pedagógica efetiva. Tal estratégia pode ser compreendida como aprendizagem híbrida, que confere mais flexibilidade ao aluno do que apenas nas aulas presenciais, promove facilidade de acesso ao conteúdo e integração de multimídias e tecnologias digitais em diversas perspectivas (Weber, \& Santos, 2013; Freeman, Adams Becker, \& Hall, 2015).

Diante desse panorama, as relações de aprendizagem vêm se alterando sensivelmente, desestabilizando a compreensão tradicional sobre o ensino. Com o suporte das tecnologias digitais, a comunicação educativa, inerente à prática pedagógica, ganhou nova dimensão. O espaço de comunicação/relação entre professores e alunos, antes restrito à sala de aula, foi ampliado com os ambientes virtuais de 
aprendizagem e suas ferramentas (chats, fóruns de discussão, blogs etc.), que passaram a ser percebidos como elementos possíveis em práticas didático-pedagógicas.

Dessa forma, o Projeto Político Pedagógico (PPP) do curso de Enfermagem do campus Centro-Oeste Dona Lindu, da Universidade Federal de São João del-Rei (CCO/UFSJ), iniciado em 2008, apresenta uma proposta de abordagem significativa e interdisciplinar numa perspectiva dinâmica de integração com os aspectos teóricos e metodológicos. Esse projeto permite que o professor valorize o conhecimento prévio do aluno, considerando sua realidade e sua forma de aprender.

As estratégias de ensino e aprendizagem do PPP passam por atividades expositivoparticipativas dentro das salas de aulas e dos laboratórios, acessos a biblioteca e recursos de informática para complementação dos estudos, além de práticas em serviço nas unidades de atendimento no município.

As unidades curriculares são divididas em eixos de conhecimento como Ciências Biológicas e da Saúde, Ciências Humanas e Sociais e Ciências da Enfermagem. Dentro do primeiro eixo o conteúdo de Biologia Celular é ministrado juntamente com parte dos conteúdos de Anatomia, Histologia, Bioquímica, Fisiologia e Microbiologia na Unidade Curricular Bases Biológicas da Prática em Enfermagem (BBPE). Essa unidade curricular constitui-se com carga horária de 153 horas distribuídas entre teoria e prática, ministrada por diferentes professores.

Contudo, a abordagem dos conteúdos da unidade curricular BBPE, por se tratar de diversas disciplinas que são ministradas em conjunto e de forma integrada, chega a ser uma surpresa para os alunos, fazendo com que haja uma dificuldade inicial de entendimento, principalmente para aqueles que só tiveram vivências de práticas de ensino e aprendizagem numa perspectiva conservadora/tradicional na educação básica.

Uma possibilidade de abordagem dos conteúdos, em consonância com o atual contexto sociotécnico, é por meio do Moodle. Trata-se de um recurso digital que viabiliza a disponibilização e o desenvolvimento dos conteúdos de um curso através de funcionalidades que o caracterizam como um ambiente virtual de aprendizagem (AVA); é uma ferramenta que permite a realização de avaliações, pesquisas de opinião, questionários, tarefas, salas de bate-papo, fóruns, mensagens, workshops e a criação de textos colaborativos (Martins, \& Campestrini, 2004). Pode ainda vincular fatores como interatividade, integração de recursos, serviços didáticos e comunicação. 
Assim, a realização de aulas que possam ser dinâmicas, viabilizadas através de recursos digitais em ambientes virtuais, pode contribuir com uma maior "aproximação" entre aluno, professor e tutor (que atuaria como monitor), permitindo a interatividade e favorecendo a participação e o envolvimento do aluno em um ambiente de EaD, em um novo contexto de proposta pedagógica.

Os alunos têm, nesse ambiente virtual, todo o conteúdo disponível para estudar a qualquer momento e as atividades a ele associadas que podem auxiliá-los a verificar seus conhecimentos na área. Os alunos contam também com um tutor, que deve estar disponível on-line para discutir os assuntos tratados.

Nesse sentido, a proposta do curso era estruturar e ministrar aulas de Biologia Celular por meio de um ambiente virtual de aprendizagem. O objetivo era utilizar o Moodle como estratégia pedagógica na abordagem dos conteúdos de forma mais dinâmica e interativa que no ensino presencial, favorecendo a flexibilidade, a liberdade e a autonomia no desenvolvimento da aprendizagem dos estudantes envolvidos.

\section{Desenvolvimento da Proposta}

Parte de um projeto chamado "UFSJ Virtual" (Edital n 15/2010 - Capes/UAB) foi realizado durante dois semestres para compreender o processo de estruturação e execução de aulas do conteúdo de Biologia Celular, na unidade curricular BBPE, do curso de Enfermagem da UFSJ, situado na cidade de Divinópolis (MG).

Para o desenvolvimento e exposição do curso, dois tutores docentes da referida universidade foram capacitados pelo Núcleo de Educação a Distância (Nead), da própria instituição. Essa capacitação ocorreu durante dois meses com encontros presenciais e a distância.

Nos quatro meses seguintes ao curso de capacitação, as aulas foram elaboradas a partir de pressupostos associados à concepção pedagógica de EaD de acordo com Bastos e Guimarães (2003). Essa concepção visa ao planejamento didático, seleção de conteúdos adequados para os alunos, construção de material didático consoante à concepção pedagógica adotada, facilidade do estabelecimento de uma relação dialógica entre tutores e alunos através de tecnologias interativas de comunicação e a possibilidade de o professor ser um facilitador do processo de ensino e aprendizagem. 
Nesse sentido, os tutores basearam os textos das aulas em livros didáticos e experiências em sala de aula, formatando-os em tópicos modulares em um editor de texto, procurando sempre relacioná-los com a experiência adquirida pelo aluno ao longo do ensino fundamental e médio. Os textos foram associados a vídeos e figuras retiradas da internet para facilitar a relação dialógica.

Foram construídos nove módulos; ao término de cada um, questões ou situaçõesproblemas foram disponibilizadas para que houvesse uma atividade síncrona (um debate em formato de chat) e, assim, uma observação do tutor acerca da aprendizagem dos alunos.

As aulas foram idealizadas, planejadas e postadas na plataforma Moodle disponibilizada pelo Nead/UFSJ, entre os meses de março e julho de 2011, com participação contínua dos dois professores de BBPE.

As atividades foram expostas para todos os 36 alunos ingressantes, por meio de processo seletivo, no curso de Enfermagem, no segundo semestre do ano letivo de 2011 da UFSJ. A capacitação dos alunos ocorreu nos mesmos moldes do treinamento dos tutores pelo Nead/UFSJ realizado no Moodle.

Para acessar o ambiente virtual, cada aluno foi cadastrado no sistema e recebeu a senha de acesso. Os diferentes temas de Biologia Celular foram organizados de forma lógica considerando o grau de dificuldade. Na página inicial, foram disponibilizados conteúdos referentes à Introdução a EaD, visto que a maioria dos alunos relatou não ter experiência prévia com esse tipo de ambiente de estudo. Na sequência, foram disponibilizadas as páginas dos conteúdos: (1) Apresentação do curso de nivelamento em Biologia; (2) História, evolução, organização e método de estudo de células; (3) Citoesqueleto, centríolos, lisossomos e citosol; (4) Membranas e suas especializações; (5) Organelas citoplasmáticas; (6) Permeabilidade celular; (7) Organelas: mitocôndria; (8) Núcleo e material genético; (9) Ciclo e divisão celular. Cada um dos assuntos continha de uma a sete subáreas, nas quais o tema era abordado de forma sucinta.

O tutor ficou disponível no laboratório de informática da universidade, presencialmente, duas horas por semana, em horário no qual os estudantes não tinham aulas presenciais regulares do curso, para que pudesse auxiliá-los tanto em relação aos conteúdos específicos da unidade curricular como nas questões referentes ao uso do AVA. 


\section{Resultados e Discussão}

Após o curso do Moodle, os tutores puderam estudar, interagir e praticar dentro da plataforma utilizada, o que facilitou a dinâmica de produção das aulas e a comunicação com os alunos durante a realização do curso (Figura 1 e 2).

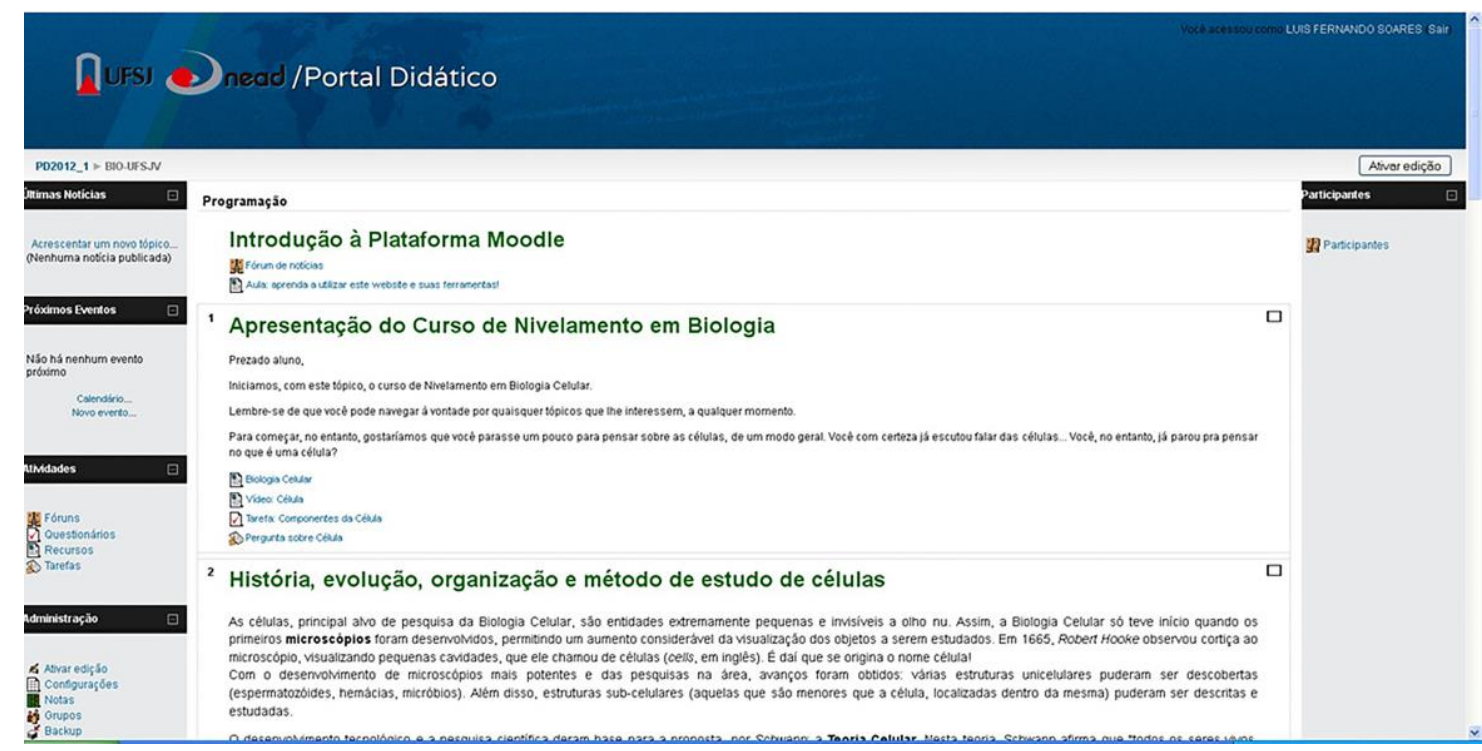

Figura 1: Tela na plataforma Moodle apresentando os conteúdos de Biologia do projeto UFSJ-Virtual.

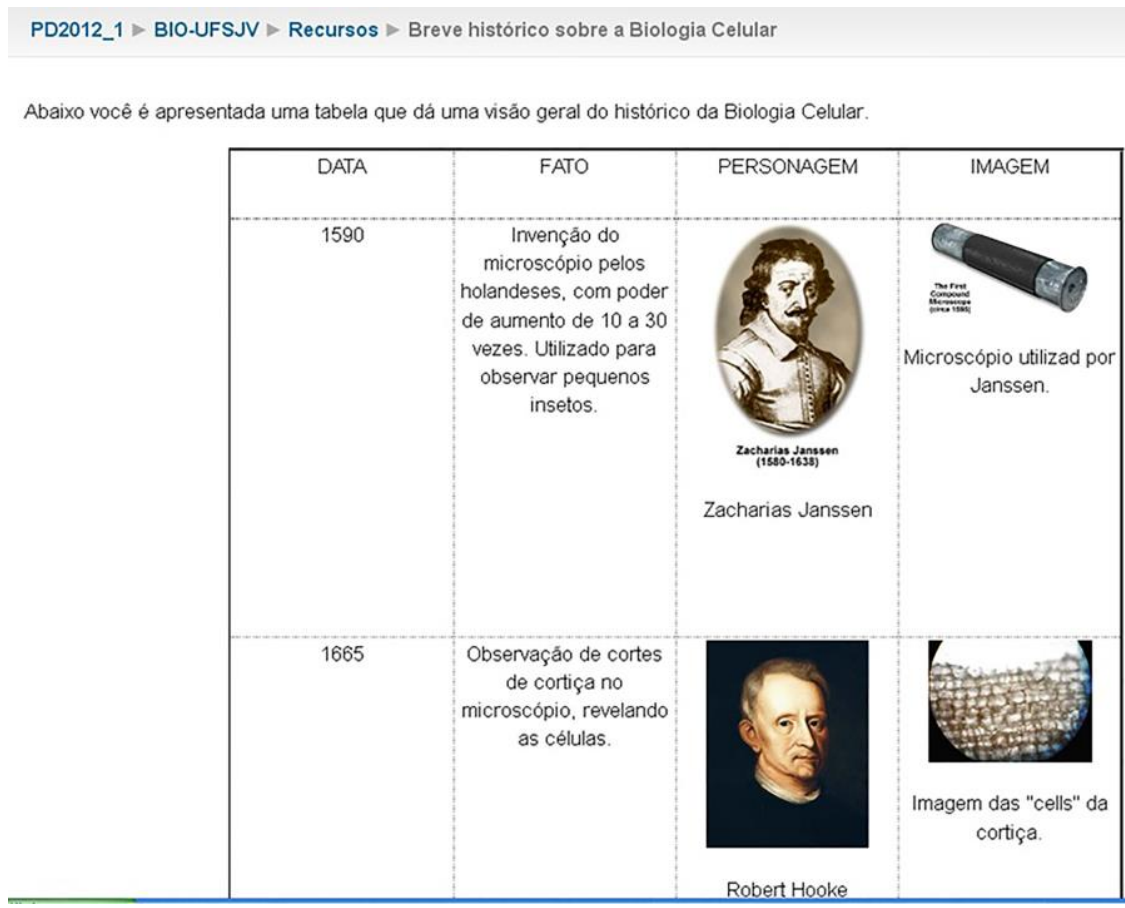

Figura 2: Exemplo do formato dos textos didáticos apresentados no curso virtual de Biologia. 
A modalidade presencial, sem auxílio de tutoria na unidade curricular BBPE, mostra um menor rendimento dos alunos nessa unidade, tanto na turma precedente (I 12011 e II 2 2011) quanto na subsequente (I 12012 e II 2 2012), denotando certa dificuldade dos alunos no processo de aprendizagem (Tabela 1). Os dados na tabela também mostram que as menores notas alcançadas pelos alunos do curso híbrido foram maiores que as menores notas dos alunos das outras turmas. Como não houve mudança no método de ensino, dos professores e nas avaliações, podemos inferir que os alunos participantes da tutoria apresentaram uma base mais consolidada que aquelas turmas que não participaram. Essa inferência decorre de relato do instrutor, cuja experiência no contato com os estudantes o levou a acreditar que, nos processos de discussão através da plataforma, foi observada uma mudança de postura dos estudantes, na qual os alunos estariam "aprendendo a estudar e aprendendo a aprender".

Tabela 1: Análise descritiva das notas dos alunos em dois períodos de Bases Biológicas da Prática em Enfermagem durante os anos de 2011 e 2012.

\begin{tabular}{c|c|c|c|c|c}
\hline \multirow{2}{*}{$\begin{array}{c}\text { BBPE } \\
\text { Período/Semestre/Ano }\end{array}$} & \multirow{2}{*}{$\begin{array}{c}\text { Número de } \\
\text { alunos }\end{array}$} & \multicolumn{3}{|c|}{ Valores das notas } & \multirow{2}{*}{-valor } \\
\cline { 3 - 6 } & & Média & Mínimo & Máximo & \\
\hline I/1/2011 & 39 & 60,5 & 35 & 79,9 & $0,006 *$ \\
\hline I/2/2011 & 36 & 72,0 & 58 & 86,3 & \\
\hline I/1/2012 & 38 & 69,1 & 42,7 & 83,6 & 0,237 \\
\hline II/2/2011 & 37 & 63,2 & 18,3 & 83,7 & 0,081 \\
\hline II/1/2012 & 34 & 68,3 & 25 & 85,9 & - \\
\hline II/2/2012 & 33 & 56,6 & 8,2 & 77,1 & $0,016 *$ \\
\hline
\end{tabular}

* Dado estatisticamente significativo

Ao avaliarmos o Gráfico 1, podemos notar maior variabilidade de notas nas turmas do curso de Enfermagem durante o $2^{\circ}$ semestre do curso ( 3 caixas da direita) quando comparadas às do $1^{\circ}$ semestre do curso ( 3 caixas da esquerda). Esse padrão é observado 
tanto nas turmas que não participaram da experiência EaD quanto na que participou, o que pode representar maior dificuldade de parte dos alunos em manter a performance nas avaliações quando avançam no nível do curso. No entanto, com base nos dados da Tabela 1, podemos afirmar que a turma que passou pelo processo de aprendizado a distância manteve uma performance acima das demais, mesmo no semestre seguinte, quando já não havia mais esse tipo de acompanhamento. Tais fatos talvez demonstrem que o "aprender a aprender" citado anteriormente configurou-se como uma mudança de atitudes de longa duração.

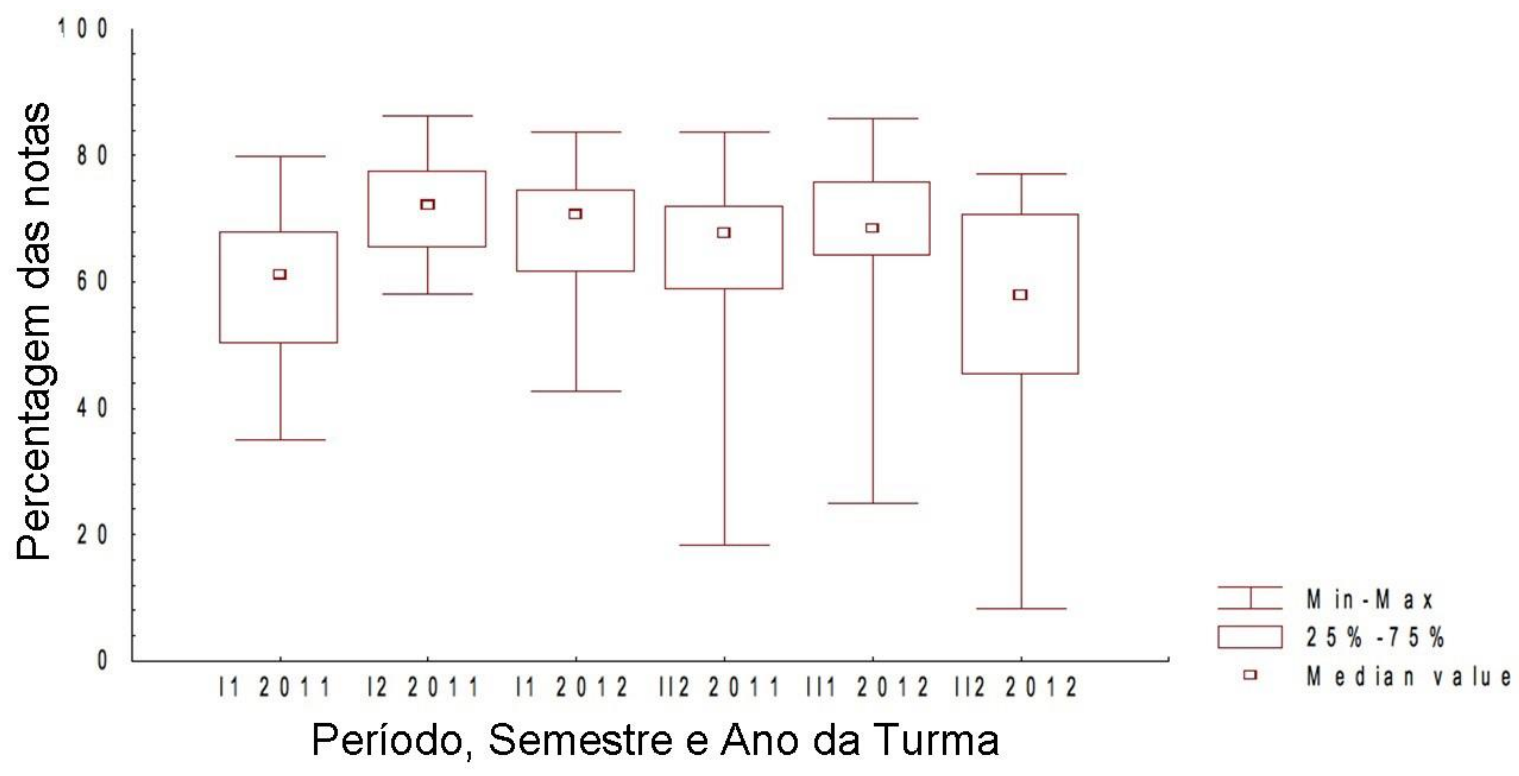

Gráfico 1: Box plot das notas dos alunos em dois períodos de Bases Biológicas da Prática em Enfermagem durante os anos de 2011 e 2012.

Apesar de não ter havido procura presencial pelo tutor, houve participação dos alunos diariamente na plataforma. Isso foi estimulado pelos tutores por meio das discussões em fóruns e de respostas a eventuais questões. Além disso, os alunos também eram lembrados das tarefas propostas. A preferência em participar a distância pode ser devida à maior liberdade de se envolver nas atividades e opinar sobre os assuntos, sem a presença de colegas, e também ao fato de o ambiente virtual ser mais confortável para o aluno se expressar por diferentes formas (Cavalcante, Ferreira, Maia, Araújo, \& Silveira, 2012; Barros, \& Ferreira-Neto, 2010). 
Durante os 100 dias letivos de aula no semestre, todos os estudantes acessaram os conteúdos on-line, contudo, o período de acesso iniciou no $11^{\circ}$ dia de aula sendo que o último dia de acesso pelos alunos ocorreu no $74^{\circ}$ dia, com média de 47 dias de acesso dos alunos (Figura 3). As atividades mais acessadas por todos os alunos foram os questionários sobre os componentes celulares e a bioquímica celular (989 acessos, 36 alunos), seguidas por tarefas com pontuação no curso (405 acessos em média por tarefa) e a visualização de conteúdos (480 acessos). Vinte alunos participaram em fóruns de discussão com um total de 54 acessos. Já o acesso às páginas com conteúdo didático, vídeos e figuras foi bem mais restrito, no sentido de que, apesar de o número de visualizações ter sido relativamente grande, esse número foi gerado por apenas oito alunos quando comparado aos vinte alunos que participaram dos fóruns (em média 11 acessos por oito alunos). Assim, é possível constatar que atividades com finalidade avaliativa promovem mais participação do aluno do que as que não têm essa finalidade. Esse aspecto precisa ser analisado mais detidamente, pois essa participação não pode ficar restrita a cobranças específicas, principalmente às de avaliação.

\section{BIOLOGIA - UFSJ VIRTUAL}

Processados dos logs desde sexta, 1 julho 2011, 09:15

\begin{tabular}{|c|c|c|}
\hline Atividade & Visualizaçōes & Último acesso \\
\hline Q Fórum de noticias & 119 & quarta, 14 dezembro 2011, 21:31 (279 dias 12 horas) \\
\hline C Aula: aprenda a utilizar este website e suas ferramentas! & 20 & quarta, 14 dezembro $2011,14: 49$ (279 dias 18 horas) \\
\hline \multicolumn{3}{|c|}{ Tópico 1} \\
\hline [C. Biologia Celular & 57 & sexta, 16 março $2012,15: 53$ (186 dias 16 horas) \\
\hline E Video: Célula & 42 & sexta, 16 março 2012, 15:53 (186 dias 16 horas) \\
\hline 2) Tarefa: Componentes da Célula & 458 & quinta, 15 dezembro $2011,14: 49$ (278 dias 18 horas) \\
\hline ○. Pergunta sobre Célula & 385 & sexta, 16 março 2012, $15: 47$ (186 dias 16 horas) \\
\hline \multicolumn{3}{|c|}{ Tópico 2} \\
\hline [ Breve histórico sobre a Biologia Celular & 32 & sexta, 16 março 2012, $15: 47$ (186 dias 16 horas) \\
\hline Q Especializações celulares e função celular & 520 & quinta, 15 dezembro $2011,14: 24$ (278 dias 19 horas) \\
\hline E Bioquímica Celular & 30 & segunda, 28 novembro 2011, 21:37 (295 dias 12 horas) \\
\hline (2) Bioquímica Celular & 166 & quinta, 15 dezembro $2011,12: 34$ (278 dias 21 horas) \\
\hline [C] Definição & 22 & sexta, 16 março $2012,15: 53$ (186 dias 16 horas) \\
\hline [ A célula eucariota e suas organelas & 22 & sexta, 16 março $2012,15: 53$ (186 dias 16 horas) \\
\hline [ As células procariotas & 19 & segunda, 28 novembro 2011, 22:09 (295 dias 11 horas) \\
\hline E Procarioto $\times$ Eucarioto & 27 & quarta, 30 novembro $2011,20: 33$ (293 dias 13 horas) \\
\hline
\end{tabular}

Figura 3: Tela do sistema de relatórios da plataforma Moodle indicando o número de acessos dos alunos ao ambiente da Biologia-Virtual. 
No que se refere à realização das atividades avaliativas, observou-se que a maioria dos alunos inicialmente utilizava textos encontrados na internet para responder às questões colocadas para a tarefa ou mesmo para participação nos fóruns. As respostas eram resultados de pesquisas feitas principalmente por meio do sítio de busca Google, sem o devido processo de ressignificação e de elaboração sistemática a partir das fontes consultadas. No entanto, sob a orientação do tutor, os alunos puderam aprender sobre a importância desse processo de ressignificação, de autoria, para redigirem seus próprios textos, sendo-Ihes concedidas novas oportunidades para opinarem nos fóruns e submeterem suas tarefas novamente. Após essa intervenção, foi possível constatar uma mudança de atitude por parte dos estudantes, que passaram a produzir textos com hiperlinks (hipertextos). Dessa forma, com a utilização de hipertextos através da busca por informações, o estudante, de acordo com Dias (2000), participa ativamente do processo de construção do conhecimento.

Com os avanços e a presença maciça das TDIC no atual contexto sociocultural, temos um grande volume de informação que está causando mudanças significativas na organização cultural. Isso tem exigido das instituições de ensino e dos professores a necessidade de promover estratégias que possam viabilizar as práticas dos alunos na realização de propostas pedagógicas que sejam efetivas para a aprendizagem e não simplesmente o cumprimento de tarefas específicas, em função da avaliação (Almeida, 2003; Peeraer, \& Petegem, 2011).

\section{Considerações Finais}

É atribuído ao professor um conjunto muito grande de tarefas, visando fornecer aos estudantes uma formação o mais completa possível, que reúne, dentre outras, dimensões cognitivas, morais, éticas, políticas - modos peculiares de orientar a aprendizagem e criar cenários mais favoráveis à construção do conhecimento (Veiga, 2006).

Vivemos um constante processo de reconfiguração nas práticas sociais com grande presença das TDIC e das mídias digitais em nosso cotidiano. Esse processo interfere decisivamente em diversas práticas, como nas formas de relacionamento, no acesso à informação e, consequentemente, na construção do conhecimento. 
Como profissionais da educação, o nosso envolvimento deve estar voltado para o processo permanente de debate e busca de entendimento sobre as transformações que vivenciamos, dos problemas enfrentados e das reais condições que nos permitam atuar em conformidade com as demandas contemporâneas, orientados para ações que sejam significativas e qualitativas na prática docente.

Os modelos tradicionais de ensino ainda predominam nas escolas e universidades, as aulas centradas nos professores precisam ser substituídas por propostas que levem em consideração as mudanças dos alunos desse atual contexto, que falam na linguagem digital dos computadores, videogames e internet. "Os alunos de hoje não são mais as pessoas para as quais nossos sistemas educacionais foram projetados, e em virtude disso a escola tem ensinado habilidades do passado" (Mattar, 2010, p. 10).

A utilização de recursos digitais na abordagem de conteúdos pode contribuir para uma educação mais centrada no aluno. O professor deixa de ser a fonte de conhecimento e passa a ser o estimulador da busca pelo saber, incentivando os estudantes a realizarem discussões e atividades que os levem a um crescimento educacional com mais flexibilidade e autonomia que na abordagem tradicional de ensino (Haddad, 2013).

Nesse sentido, foi possível constatar com a experiência do curso de Enfermagem da UFS que a utilização do Moodle, como ambiente virtual de aprendizagem e suporte no desenvolvimento de atividades em cursos presenciais, pode contribuir com o processo de abordagem dos conteúdos, favorecendo a construção do conhecimento dos estudantes universitários. Trata-se de uma proposta pedagógica em consonância com as transformações que vivenciamos no atual contexto sociocultural, promovendo maior envolvimento dos alunos nas práticas de ensino e aprendizagem.

De acordo com estudo realizado por Haddad (2013) sobre a utilização do Portal Didático do Nead/UFSJ em cursos presenciais, os estudantes aprovam as funcionalidades e os recursos desse ambiente virtual de aprendizagem, principalmente por favorecer a comunicação com o professor, permitir o acesso ao material da disciplina, facilitar, na realização de atividades, a obtenção de notícias e informações sobre a disciplina e, ainda, pelas possibilidades de interação. Por tudo isso, temos um recurso com potencial significativo no desenvolvimento da nossa atividade pedagógica. 
Diante de um cenário com amplas possibilidades e necessidades de integração das mídias em vários aspectos nos espaços individuais, sociais e profissionais, as escolas e universidades são chamadas a repensarem seus compromissos e propostas pedagógicas.

\section{Agradecimentos}

Agradecemos à Coordenação de Aperfeiçoamento de Pessoal de Nível Superior (Capes), pela liberação de fomento, através do Edital № 15/2010 No âmbito do Sistema Universidade Aberta do Brasil (UAB).

\section{Referências Bibliográficas}

Almeida, M. E. B. (2003). Educação a distância na internet: abordagens e contribuições dos ambientes digitais de aprendizagem. Educação e Pesquisa, 29(2), 327-340.

Barros, C. C., Ferreira-Neto, J. L. (2010). Adolescência e msn: o arranjo tecnológico da subjetividade. Pesquisas e práticas psicossociais, 5(1), 30-38.

Bastos, M. A. R., Guimarães, E. M. P. (2003). Educação a distância na área da enfermagem: relato de uma experiência. Revista Latino-Americana de Enfermagem, 11(5), 685-691.

Brasil. (2002). Conselho Nacional de Educação, MEC. Câmara de Educação Básica. Diretrizes Nacionais para a Educação a Distância no âmbito da Educação Básica. Relatores: Gouveia, S. F. e Bizzo, N. M. V. Brasília: CNE/MEC.

Cavalcante, R. B., Ferreira, M. N., Maia, L. L. Q. G. N., Araújo, A., Silveira, R. C. P. (2012). Uso de Tecnologias da Informação e Comunicação na educação em saúde de adolescentes escolares. Journal of Health Informatics, 4(4), 182-186.

Dias, P. (2000). Hipertexto, hipermédia e media do conhecimento: representação distribuída e aprendizagens flexíveis e colaborativas na web. Revista Portuguesa de Educação, 13 (1), 141-167. Disponível em http://repositorium.sdum.uminho.pt/handle/1822/497 
Freeman, A., Adams Becker, S., Hall, C. (2015). NMC Technology Outlook for Brazilian Universities: A Horizon Project Regional Report. Austin, Texas: The New Media Consortium.

Haddad, M. (2013). Ambientes virtuais de aprendizagem (AVAs) no ensino presencial e semipresencial de graduação da UFSJ. Dissertação de mestrado. Universidade Federal de São João del-Rei.

Inocêncio, M. (2012). O e-learning: uma prática pedagógica desafiadora na Uni-CV. Educação, Formação \& Tecnologias, 5(1), 33-46. Disponível em http://eft.educom.pt/index.php/eft/issue/view/16.

Lima, L. C., Azevedo, M. L. N., Catani, A. M. O. (2008). Processo de Bolonha, a avaliação da educação superior e algumas considerações sobre a universidade nova. Avaliação, 13(1), 7-36.

Martins, J. G., Campestrini, B. B. (2004). Ambiente virtual de aprendizagem favorecendo o processo ensino-aprendizagem em disciplinas na modalidade de educação à distância no ensino superior. In $11^{\circ}$ Congresso Internacional de Educação a Distância. Salvador, $\quad$ BA. Disponível em http://www.abed.org.br/congresso2004/por/htm/072-TC-C2.htm

Mattar, J. (2010). Games em educação: como os nativos digitais aprendem. São Paulo: Pearson Prentice Hall.

Moodle. História do Moodle. Acesso em: 20 jun. 2015, disponível em http://docs.moodle.org/all/pt br/História do Moodle

Peeraer, J., Petegem, P. V. (2011). ICT in teacher education in an emerging developing country: Vietnam's baseline situation at the start of "The Year of ICT". Computers \& Education, 56 (4), 974-982.

Veiga, I. P. A. (2006). Ensinar: uma atividade complexa e laboriosa. In I. P. A. Veiga (Org.) Lições de Didática (pp. 13-34). Campinas: Papirus.

Weber, A., Santos, E. (2013). Educação Online em tempos de mobilidade e aprendizagem ubíqua: desafios para as práticas pedagógicas na cibercultura. Revista EDaPECi, 13(2), 168-183. 